\title{
Effect of Cyanocobalamin on Antioxidant Enzymes of Male Wistar Albino Rats Infected with Trypanosoma brucei brucei
}

\author{
Edoga C. O. ${ }^{1, *}$, Eyo J. E. ${ }^{2}$, Anukwuorji C. A. ${ }^{3}$, Nzewi J. I. ${ }^{4}$ \\ ${ }^{1}$ Department of Applied Biology and Biotechnology, Enugu State University of Science and Technology (ESUT), Nigeria \\ ${ }^{2}$ Department of Zoology and Environmental Biology, University of Nigeria, Nsukka, Nigeria \\ ${ }^{3}$ Department of Botany, Nnamdi Azikiwe University, Awka, Nigeria \\ ${ }^{4}$ EKG Technician Program, California State University, East Bay, Oakland Campus, CA, USA
}

Received April 18, 2020; Revised May 16, 2020; Accepted May 27, 2020

Copyright $(2020$ by authors, all rights reserved. Authors agree that this article remains permanently open access under the terms of the Creative Commons Attribution License 4.0 International License

\begin{abstract}
The study was undertaken to check the effects of cyanocobalamin on antioxidant enzymes of male Wistar albino rats infected with $T$. b. brucei. Fifty-four (54) male Wistar albino rats were divided into six groups of three rats each which were replicated three times. The rats were marked and kept in stainless wire cages labeled A-F. Groups $\mathrm{A}, \mathrm{B}$, and $\mathrm{C}$ were normal, negative and standard control respectively. Groups D, E and F were infected with $1.0 \times 10^{6}$ trypanosomes and treated with $0.2 \mathrm{mg} / \mathrm{kg}$ (low-dose), $0.3 \mathrm{mg} / \mathrm{kg}$ (enriched-dose), and $0.4 \mathrm{mg} / \mathrm{kg}$ (high-dose) body weight of vitamin $\mathrm{B}_{12}$ respectively. The experiment lasted for twenty-one days from the day T. $b$. brucei infection was established. A sample of heart tissue homogenate was collected weekly across the groups and subjected to biochemical determination of catalase, superoxide dismutase (SOD), glutathione reductase, and glutathione peroxidase concentrations. There were significant differences in the effect of cyanocobalamin on the concentrations of cardiac tissue antioxidant enzymes which were also dependent on the duration of the experiment. At post-treatment, catalase, superoxide dismutase, and glutathione reductase levels differed significantly $(\mathrm{p}<0.05)$ from the negative control. There were significant reductions in the levels of catalase, glutathione reductase, glutathione peroxidase, and rise in the SOD level as infections grow. The result, however, showed that cyanocobalamin caused a significant elevation in the catalase, glutathione reductase, reduction in the concentration of SOD and no change in the level of glutathione peroxidase following treatments with cyanocobalamin. In conclusion, there were significant reductions in the level of SOD, evidenced in an increase in the catalase and glutathione reductase levels, and no change in the glutathione peroxidase concentration
\end{abstract}

following treatments with cyanocobalamin.

Keywords Trypanosoma brucei brucei, SOD, Cyanocobalamin, Catalase, Glutathione Reductase, Glutathione Peroxidase

\section{Introduction}

Human African Trypanosomiasis (HAT) is one of the tropical diseases that are widespread in Africa (Welburn and Maudlin, 2012). The primary reason for the diagnosis of HAT is to enable researchers to device an appropriate means of therapeutic and prophylactic management. The diagnosis involves three steps: screening, diagnostic confirmation and staging. HAT manifests in two stages; the first (haemolymphatic) stage, where parasites are found in the blood and lymphatic tissues (Brun et al., 2010). The last (meningoencephalitic) stage is characterized by the presence of trypanosomes in the central nervous system (Brun et al., 2010). HAT is a dreadful disease with severe pathological consequence (Jamonneau et al., 2012). The transmission of HAT is mostly cyclical, which is dependent on the interactions of pathogenic parasites, tsetse flies, and mammalian reservoirs (WHO, 2013). Oxidative stress is a common mediator in the pathogenicity of established cardiovascular risk factors (Edwin et al., 2013). The sera of camels infected with trypanosomes recorded a significant decrease in SOD concentration (El-Deeb and Esmoslemany, 2015). The reduced SOD level might be a result of its depletion during oxidative stress caused by $T$. envasi. Catalase is an enzyme found in animals exposed to oxygen. It is used by cells to metabolize 
the decomposition of hydrogen peroxide into less reactive gaseous oxygen and water (Chelikani et al., 2004). It is an important enzyme that protects the cell from damage caused by reactive oxygen species (ROS). Glutathione reductase (GR) is an enzyme that catalyzes the reduction of glutathione disulfide (GSSG) to the sulfhydryl form glutathione (GSH), thereby maintain the cell integrity by reducing the oxidative damage caused by ROS (Deponte, 2013). Glutathione peroxidase (GPx) is a cytosolic enzyme that maintains cellular redox equilibrium and protects the organism from oxidative damage. The biological function is to reduce free hydroperoxides to their corresponding alcohols and to reduce free hydrogen peroxide to water (Kannan et al., 2011). Vitamin $\mathrm{B}_{12}$ in the form of cyanocobalamin can be given parenterally as a prescriptive medication, usually by intramuscular injection (Andres et al., 2007). Cyanocobalamin functions in red blood cell formation, neurologic, and cognitive regulations (Koury and Ponka, 2004). Its role has been established in subjects suffering from diabetic neuropathy (Sun et al., 2005). It also functions in nervous regulation and for the metabolism of carbohydrates, protein, fat, and maintenance of fertility. Intramuscular injection of cyanocobalamin has proven effective in increasing sperm counts for men undergoing intracytoplasmic sperm injection (ICSI) procedure (Boxmeer et al., 2007). The deficiency of vitamin $\mathrm{B}_{12}$ is associated with the pathogenesis of megaloblastic anemia, fatigue, weakness, constipation, loss of appetite, weight loss, and subacute combined degeneration of the spinal cord (Lanska et al., 2009).

\section{Materials and Method}

\subsection{Animal Model and Experimental Protocol}

Fifty-four (54) male albino Wistar rats (Rattus norvegicus) aged 3 months, weighing between $180-220 \mathrm{~g}$ were procured, housed and allowed to acclimatize for two weeks at the Pharmacy-Animal House, Madonna University Elele, Rivers state. The rats were grouped into six (6) cages labeled A-F and each cake has three (3) rats that were replicated three (3) times from each group. The animals were kept under normal room temperature with $a d$ libitum access to feed and water. The cages were cleaned daily to prevent infection of the animals and to minimize extraneous variables. The groups (A-F) were as thus: Group A (Normal Control) were neither infected with trypanosomes nor treated with vitamins; Group B (Negative Control) were infected with $1.0 \times 10^{6}$ trypanosomes but not treated; Group C (Standard Control) were infected with $1.0 \times 10^{6}$ trypanosomes and treated with $0.2 \mathrm{mg} / \mathrm{kg}$ Diminazene aceturate body weight); Group D (Low-dose of vitamin $\mathrm{B}_{12}$ ) were infected with $1.0 \times 10^{6}$ trypanosomes and treated with $0.2 \mathrm{mg} / \mathrm{kg}$ body weight of vitamin $\mathrm{B}_{12}$; Group $\mathrm{E}$ (Enriched dose of vitamin $\mathrm{B}_{12}$ ) were infected with $1.0 \times 10^{6}$ trypanosomes and treated with 0.3 $\mathrm{mg} / \mathrm{kg}$ body weight of vitamin $\mathrm{B}_{12}$; Group F (High dose of vitamin $B_{12}$ ) were infected with $1.0 \times 10^{6}$ trypanosomes and treated with $0.4 \mathrm{mg} / \mathrm{kg}$ body weight of vitamin $B_{12}$. The experiment lasted for twenty-one days after Trypanosoma brucei brucei infection was established. A sample of cardiac tissue homogenate was collected weekly from the three (3) rats across the groups and taken to Divine Chemicals and Analytical Laboratory, Nsukka for biochemical determination of catalase, SOD, GR, and GPx concentrations.

\subsection{Procurement and Inoculation of Trypanosomes}

Trypanosoma brucei brucei was obtained from an experimentally infected rat previously inoculated with the parasite from the Faculty of Veterinary Medicine, UNN. Each experimental rat was administered $0.1 \mathrm{ml}$ of infected blood in $0.3 \mathrm{ml}$ normal saline containing $1 \times 10^{6}$ trypanosomes using the rapid matching method (Herbert and Lumbsden, 1976) to determine the level of parasitemia. Inoculation was done intraperitoneally.

\subsection{Determination of Parasitaemia}

Wet blood preparation was covered with a coverslip on a slide and examined under X40 and oil immersion using a microscope at X100 magnification. The identification of parasites was done using morphological description (Van-Wyk and Mayhew, 2013).

\subsection{Formulation and Administration of Vitamin $B_{12}$}

Vitamin $B_{12}$ (cyanocobalamin) was procured at Science Line, New Parts, Onitsha, Anambra State, Nigeria in a powdered bottle. The working concentrations were determined at the Department of Biochemistry, Madonna University, Elele. From the result of acute oral toxicity $\left(\mathrm{LD}_{50}\right)$ test of vitamin $\mathrm{B}_{12}$ as thus:

Mild dose: $0.2 \mathrm{mg} / \mathrm{kg}$ b.w.d.

Enriched dose: $0.3 \mathrm{mg} / \mathrm{kg}$ b.w.d.

High dose: $0.4 \mathrm{mg} / \mathrm{kg}$ b.w.d.

The working concentrations were administered via intubation using $2 \mathrm{ml}$ of distilled water as a vehicle.

\subsection{Standard Drug}

Diminazene aceturate was procured from the Faculty of Veterinary Medicine Clinic, University of Nigeria, Nsukka, Nigeria in a $2.36 \mathrm{~g}$ granules. The working dosage was $0.2 \mathrm{~m} / \mathrm{kg}$. The administration was intravenous.

\subsection{Preparation of Cardiac Tissues Homogenate}

The heart was weighed and homogenized with a potter-Elvenhjem tissue homogenizer in a $10 \mathrm{mM}$ potassium phosphate buffer ( $\mathrm{pH}$ 7.4). The crude tissue homogenate was centrifuged at 10,000 revolutions per 
minute, for 15 minutes in a cold centrifuge, and the resultant supernatant was used for the different estimations of proteins.

\subsubsection{Catalase Activity}

Catalase activity was determined in erythrocyte lysate using Aebi's method (Aebi, 1984).

\subsubsection{Determination of Superoxide Dismutase (SOD)}

The method illustrated by McCord and Fridovich (1969) was used for the determination of superoxide dismutase (SOD).

\subsubsection{Glutathione Reductase (GR) Assay}

The method illustrated by Kakkar et al. (1984) was followed in the determination of glutathione reductase.

\subsubsection{Glutathione Peroxidase (GPx)}

The procedure according to Wood (1970) was used in the estimation of glutathione peroxidase concentration.

\section{Result}

Table 1-3 show the effects of cyanocobalamin on cardiac tissue while Table 4 shows the effects of Vitamin $B_{12}$ on cardiac tissue. Generally, there are significant differences on the effects of cyanocobalamin and Vitamin $B_{12}$ across the six groups of rat but there was no significant differences with respect to the weeks.

Table 1. Effect of cyanocobalamin on cardiac tissue catalase level $(\mathrm{u} / \mathrm{mg})$

\begin{tabular}{cccc}
\hline Groups & Week 1 & Week 2 & Week 3 \\
\hline A & $49.423 \pm 0.190^{\mathrm{a} 1}$ & $50.155 \pm 0.481^{\mathrm{a} 1}$ & $51.412 \pm 1.237^{\mathrm{a} 1}$ \\
B & $42.252 \pm 0.064^{\mathrm{b} 1}$ & $40.510 \pm 0.340^{\mathrm{b} 2}$ & $38.345 \pm 0.191^{\mathrm{b3}}$ \\
C & $48.131 \pm 0.017^{\mathrm{c} 1}$ & $49.435 \pm 0.156^{\mathrm{c} 1}$ & $49.527 \pm 0.507^{\mathrm{c} 1}$ \\
D & $44.833 \pm 0.059^{\mathrm{d} 1}$ & $43.682 \pm 0.117^{\mathrm{d} 1}$ & $43.571 \pm 0.058^{\mathrm{d} 1}$ \\
E & $44.980 \pm 0.173^{\mathrm{d} 1}$ & $43.780 \pm 0.114^{\mathrm{d} 1}$ & $43.674 \pm 0.118^{\mathrm{d} 1}$ \\
F & $45.483 \pm 0.117^{\mathrm{d} 1}$ & $43.824 \pm 0.118^{\mathrm{d} 1}$ & $43.751 \pm 0.116^{\mathrm{d} 1}$ \\
\hline
\end{tabular}

In a column, mean value with the same letter as superscript is not significantly different $(\mathrm{p}>0.05)$. In a row, mean value with the same number as superscript is not significantly different $(\mathrm{p}>0.05)$.

Table 2. Effect of cyanocobalamin on cardiac tissue SOD level (u/mg)

\begin{tabular}{cccc}
\hline Groups & Week 1 & Week 2 & Week 3 \\
\hline A & $3.444 \pm 0.095^{\mathrm{a} 1}$ & $3.526 \pm 0.162^{\mathrm{a} 1}$ & $3.460 \pm 0.167^{\mathrm{a} 1}$ \\
B & $3.216 \pm 0.136^{\mathrm{b} 1}$ & $4.972 \pm 0.039^{\mathrm{b} 2}$ & $5.002 \pm 0.096^{\mathrm{b} 2}$ \\
C & $3.485 \pm 0.057^{\mathrm{a} 1}$ & $3.657 \pm 0.071^{\mathrm{a} 1}$ & $3.635 \pm 0.090^{\mathrm{a} 1}$ \\
D & $3.992 \pm 0.005^{\mathrm{c} 1}$ & $4.044 \pm 0.065^{\mathrm{c} 2}$ & $4.111 \pm 0.003^{\mathrm{c} 2}$ \\
E & $3.978 \pm 0.007^{\mathrm{c} 1}$ & $3.977 \pm 0.035^{\mathrm{c} 2}$ & $4.071 \pm 0.032^{\mathrm{c} 2}$ \\
F & $3.949 \pm 0.029^{\mathrm{c} 1}$ & $4.001 \pm 0.066^{\mathrm{c} 1}$ & $4.001 \pm 0.002^{\mathrm{c} 1}$ \\
\hline
\end{tabular}

In a column, mean value with the same letter as superscript is not significantly different $(\mathrm{p}>0.05)$. In a row, mean value with the same number as superscript is not significantly different $(\mathrm{p}>0.05)$.

Table 3. Effect of cyanocobalamin on cardiac tissue glutathione reductase level $(\mathrm{u} / \mathrm{mg})$

\begin{tabular}{cccc}
\hline Groups & Week 1 & Week 2 & Week 3 \\
\hline A & $19.914 \pm 0.037^{\mathrm{a} 1}$ & $20.186 \pm 0.315^{\mathrm{a} 1}$ & $20.101 \pm 0.320^{\mathrm{a} 1}$ \\
B & $15.117 \pm 0.111^{\mathrm{b} 1}$ & $15.069 \pm 0.076^{\mathrm{b} 1}$ & $14.693 \pm 0.244^{\mathrm{b} 2}$ \\
C & $19.062 \pm 0.176^{\mathrm{c} 1}$ & $19.217 \pm 0.135^{\mathrm{c} 1}$ & $19.707 \pm 0.125^{\mathrm{c} 2}$ \\
D & $17.055 \pm 0.028^{\mathrm{d} 1}$ & $17.268 \pm 0.058^{\mathrm{d} 1}$ & $17.376 \pm 0.058^{\mathrm{d} 1}$ \\
E & $17.195 \pm 0.006^{\mathrm{d} 1}$ & $17.320 \pm 0.003^{\mathrm{d} 1}$ & $17.503 \pm 0.117^{\mathrm{d} 1}$ \\
F & $17.364 \pm 0.116^{\mathrm{d} 1}$ & $17.680 \pm 0.006^{\mathrm{d} 1}$ & $17.606 \pm 0.055^{\mathrm{d} 1}$ \\
\hline
\end{tabular}

In a column, mean value with the same letter as superscript is not significantly different $(\mathrm{p}>0.05)$. In a row, mean value with the same number as superscript is not significantly different $(\mathrm{p}>0.05)$.

Table 4. Effect of vitamin $B_{12}$ on cardiac tissue Glutathione Peroxidase (GPx) level (u/mg)

\begin{tabular}{cccc}
\hline Group & Week 1 & Week 2 & Week 3 \\
\hline A & $24.381 \pm 0.116^{\mathrm{a} 1}$ & $24.585 \pm 0.264^{\mathrm{a} 1}$ & $24.585 \pm 0.168^{\mathrm{a} 1}$ \\
B & $20.414 \pm 0.333^{\mathrm{b} 1}$ & $20.619 \pm 0.170^{\mathrm{b} 2}$ & $19.879 \pm 0.074^{\mathrm{b} 3}$ \\
C & $21.056 \pm 0.099^{\mathrm{b} 1}$ & $23.116 \pm 0.036^{\mathrm{c} 1}$ & $23.518 \pm 0.060^{\mathrm{c} 2}$ \\
D & $20.686 \pm 0.058^{\mathrm{b} 1}$ & $21.909 \pm 0.036^{\mathrm{d} 1}$ & $20.128 \pm 0.030^{\mathrm{b} 2}$ \\
E & $20.801 \pm 0.106^{\mathrm{b} 1}$ & $22.505 \pm 0.006^{\mathrm{d} 1}$ & $20.216 \pm 0.052^{\mathrm{b} 2}$ \\
F & $20.863 \pm 0.034^{\mathrm{b} 1}$ & $20.662 \pm 0.037^{\mathrm{b} 1}$ & $20.388 \pm 0.014^{\mathrm{b} 2}$ \\
\hline
\end{tabular}

In a column, mean value with the same letter as superscript is not significantly different $(\mathrm{p}>0.05$ ). In a row, mean value with the same number as superscript is not significantly different $(\mathrm{p}>0.05)$.

\section{Discussion and Conclusions}

\subsection{Discussion}

The results of the present study indicated that Trypanosoma brucei brucei caused a significant reduction in the level of antioxidant catalase in the heart tissues of Wistar albino rats (Table 1). This observation is in agreement with the work of Matheus et al. (2016) who reported a significant reduction of enzymatic activities of catalase in the heart of rats infected with $T$. evansi. They attributed these decreased enzymatic activities to cardiac injury. However, the present work conflicts with the observation of Atalay and Laaksonen (2002), who reported that under the condition of oxidative stress, the activity of catalase enzyme increases. The levels of catalase enzyme in the groups infected and treated with the antioxidant vitamin $\mathrm{B}_{12} \quad$ significantly increased the trypanosome-induced catalase reduction. The result of the 
present study also agreed with the observation of Eze et al. (2016) who reported that vitamin E supplementation significantly increases catalase activities of $T . \quad b$. brucei-infected rats. The present experiment showed a higher level of superoxide dismutase (SOD) in the heart of T. b. brucei infected rats from day 7-21 post-infection when compared to the normal control (Table 2). This is in line with the work of Atalay and Laaksonen (2002) who observed that under the condition of oxidative stress, the activity of antioxidant superoxide dismutase increases. In the infected and treated groups, there is a statistically significant difference in the activity of SOD when compared to normal control. The result of the present experiment contradicts the observation of Eze et al. (2016) who reported that antioxidant vitamin supplementation enhances SOD activities of $T$. b. brucei-infected rats. The present study showed that the proliferation of trypanosomiasis caused a reduction in the levels of glutathione reductase in the experimental group (Table 3). Previous studies measuring glutathione reductase activity showed a decrease in the parameter in chronic lymphocytic leukemia patients (Bakan et al., 2003). In the groups infected and treated with the intervention, the glutathione reductase significantly increased. The observed elevation of glutathione reductase in the treated groups is indicative of the antioxidant and trypanocidal properties of cyanocobalamin. This is consistent with the result of Verhagen et al. (2006) who reported that antioxidant vitamin can prevent the damaging effects of reactive oxygen species. The experiment showed that the proliferating parasites caused reductions of GPx in the rats (Table 4). This aligns with the works of Anschau et al. (2013) who reported decreased glutathione peroxidase activity in the blood of rats infected with $T$. evansi. In the groups infected and treated with vitamin $\mathrm{B}_{12}$, there are no significant differences in the heart tissue GPx between the treated and untreated groups. This is consistent with the findings of Clarke et al. (2007) which reported that cyanocobalamin does not affect the principal cardiovascular events.

\subsection{Conclusions}

The findings of this study indicated that the pathogenesis of $T$. brucei brucei caused a significant increase in the level of SOD, and a profound reduction in the concentrations of tissue catalase, glutathione reductase, and glutathione peroxidase (GPx). However, the administration of the rats with vitamin $\mathrm{B}_{12}$ caused dose-dependent reduction in the concentrations of SOD and increased cardiac tissue catalase and glutathione reductase, while GPx showed no significant change.

\section{REFERENCES}

[1] Aebi, H. (1984). Catalase in- vitro. Methods in Enzymology, 121-126.

[2] Andrès, E., Federici, L., Affenberger, S., Vidal-Alaball, J., Loukili, N.H., Zimmer, J., Kaltenbach, G. (2007). Vitamin $\mathrm{B}_{12}$ deficiency: a look beyond pernicious anemia. Journal of Family Practice, 56:537-42.

[3] Anschau, V., Dafre, A.L., Perin, A.P., Lagher, F., Tizatto, M.V. and Miletti, L.C. (2013). Glutathione and iron at the crossroad of redox metabolism in rats infected by Trypanosoma envasi. Parasitology Research, 112: 2361-2366.

[4] Atalay, M. and Laaksonene, D.E. (2002). Diabetes, oxidative stress, and physical exercise. Journal of Sports Science and Medicine 1(1): 1-14.

[5] Bakan, N., Taysi, S., Yilamz, O., Bakan, E., Kuskay, S., Uzun, N. (2003). Glutathione peroxidase, glutathione reductase, $\mathrm{Cu}-\mathrm{Zn}$ superoxide dismutase activities, glutathione, nitric oxide, and malondialdehyde concentrations in the serum of patients with chronic lymphocytic leukemia. Clinica Chimica Acta, 338(1-2): 143-149.

[6] Boxmeer, J.C., Smith, M., Weber, R.F., Lindemans, J., Romijn, J.C., Eijkemans, M.J., Macklon, N.S., SteegersTheunissen, R.P (2007). Seminal plasma cobalamin significantly correlates with sperm concentration in men undergoing IVF or ICSI procedures. Journal of Andrology, 28: $521-527$

[7] Brun, R., Blum, J., Chappuis, F., Burri, C. (2010). Human African trypanosomiasis. Lancet, 375(9709): 148-159.

[8] Chelikani, P., Fita, I., Loewen, P.C. (2004). Diversity of structures and properties among catalase. Cellular and Molecular Life Sciences, 61(2): 192-208.

[9] Clarke, R. (2007). Homocysteine-lowering vitamin B supplements do not improve cognitive performance in healthy older adults after two years. Evidence-Based Mental Health, 10(1): 27.

[10] Deponte, M. (2013). Glutathione catalysis and the reaction mechanisms of glutathione-dependent enzymes. Biochem. and Biophys. Acta, 1830(5): 3217-3266.

[11] Edwin, H.O., Keyvan, K.G., Chai-Chi, L., Ravi, B., Gemma, A. F. (2013). Biological markers of oxidative stress: Applications to cardiovascular research and practice. Redox Biology, 1(1): 483-491.

[12] El-Deeb, W.M., and Elmoslemany, A.M. (2015). Cardiac and Oxidative Stress Biomarkers in Trypanosoma envasi infected camels: diagnostic and prognostic prominence. Parasitology, 12: 1-6.

[13] Eze, I.J., Ajanwachukwu, N., Animoke C.P., Onoja O.S., Anosa, N.G., Eze, U.U. (2016). Immune response, anemia and oxidative stress in Trypanosoma brucei brucei-infected rats fed vitamin E supplemented diet. Anti-Infective Agents, 14(1): 28-37. 
[14] Herbert, W.J. and Lumsden, W.H.R. (1976). Trypanosoma brucei: a rapid matching method for estimating the host's parasitemia. Experimental Parasitology, 40: 427-431.

[15] Jamonneau, V., Ilboudo, H., Kabore, J., Kaba, D., Koffi, M., Solano, P., Garcia, A., Courtin, D., Laveissiere, C., Lingue, K., Buscher, P., and Buncheton, B. (2012). Untreated human infections by Trypanosoma brucei gambiense are not $100 \%$ fatal. PLoS Neglected Tropical Disease, 6(6): e1691.

[16] Kakkar, P., Das, B., and Viswanathan, P.N. (1984). A modified spectrophotometric assay of superoxide dismutase. Indian Journal of Biochemistry and Biophysics, 21: 131-132.

[17] Kannan, M., Selvaraj, R., Nirmala, S.M., Vasanthi, N. (2011). Glutathione peroxidase of Saccharomyces cerevisiae protects phospholipids during cadmium-induced oxidative stress. Antonie Van Leeuwenhoek, 99(4): 761-771.

[18] Koury, M.J. and Ponka, P. (2004). New insights into erythropoiesis: the roles of folate, vitamin $\mathrm{B}_{12}$, and iron. Annual Review of Nutrition, 24: 105-31.

[19] Lanska, D.J. (2009). Chapter 30: historical aspects of the major neurological vitamin deficiency disorders: the water-soluble B vitamins. Handbook of Clinical Neurology, 95:445-476.

[20] Matheus D.B., Carine de F.S., Claudia M.B., Karine L. da S., Thirssa H.G., Bianco C.Z.P., Daniela B.R.L., Aleksandro S.D., Ricardo E.M., Lenita M.S., and Silvia G.M. (2016). Oxidative stress in the heart of rats infected with Trypanosoma evansi. Korean Journal of Parasitology, 54(3): 247-252.

[21] McCord, J. and Fridovich, I. (1969). Superoxide dismutase, an enzymic junction for erythrocuprein. Journal of Biological Chemistry, 244: 6049-6055.

[22] Sun, Y., Lai, M.S., Lu, C.J. (2005). Effectiveness of vitamin $\mathrm{B}_{12}$ on diabetic neuropathy: a systematic review of clinical controlled trials. Acta Neurological Taiwanica, 14: 48-54.

[23] Van-Wyk, and Mayhew, E. (2013). Morphological identification of parasitic nematode infective larvae of small ruminants and cattle: A practical lab guide. Journal of Veterinary Research, 80: 1.

[24] Verhagen, H., Buijse, B., Jansen, E., Bueno-de-Mesquita, B. (2006). The state of antioxidant affairs. Nutrition Today, 41: 244-250.

[25] Welburn, S.C., and Maudlin, I. (2012). Priorities for the elimination of sleeping sickness. Advanced Parasitology, 79: 299-337.

[26] Wood J.L (1970). Fishman, Metabolic conjugation and Metabolic Hydrolysis. Academic Press, 2: 61-229.

[27] World Health Organization (2013). The 17 neglected tropical diseases. World Health Organization. http://www.who.int/neglected-diseases/diseases/en/. 